\title{
Perna canaliculus and the Intestinal Microbiome
}

\author{
Emma Tali Saltzman ${ }^{1,2}$ (D), Michael Thomsen ${ }^{1,2}$, Sean Hall ${ }^{2}$ (1) and Luis Vitetta ${ }^{1,2, *(1)}$ \\ 1 Sydney Medical School, The University of Sydney, Sydney 17200, Australia; \\ esal4025@uni.sydney.edu.au (E.T.S.); mtho0952@uni.sydney.edu.au (M.T.) \\ 2 Medlab Clinical, Sydney 17200, Australia; sean_hall@medlab.co \\ * Correspondence: luis.vitetta@sydney.edu.au or luis_vitetta@medlab.co; \\ Tel.: +61-2-8188-0311; Fax: +61-2-9699-3347
}

Received: 1 June 2017; Accepted: 26 June 2017; Published: 30 June 2017

\begin{abstract}
Natural medicines are often an attractive option for patients diagnosed with chronic conditions. Three main classes of bioactives that have been reported from marine mussel extracts include proteins, lipids and carbohydrates. Commercially, the most relevant species of marine mollusks belong to two genera, Perna and Mytilus. Specifically, the Perna canaliculus species has been repeatedly demonstrated to harbor anti-inflammatory compounds such as omega-3 polyunsaturated fatty acids ( $\boldsymbol{\omega}-3$ PUFAs) that can ameliorate pro-inflammatory conditions, or proteins that can promote thrombin inhibitory activity. Recent clinical studies have posited that extracts from green-lipped mussels may lead to prebiotic activity in the intestinal microbiome that in turn has been reported to improve symptoms of osteoarthritis of the knee. Prebiotics have been reported to favorably interact with the intestinal microbiome through the proliferation of beneficial bacteria in the gut, suppressing exogenous and endogenous intestinal infections and promoting homeostasis by balancing local pro- and anti-inflammatory actions. Bioactive compounds from Perna canaliculus are functional foods and, in this regard, may positively interact with the intestinal microbiome and provide novel therapeutic solutions for intra-intestinal and extra-intestinal inflammatory conditions.
\end{abstract}

Keywords: bioactive; Perna canaliculus; green mussel; prebiotics; functional foods; intestinal microbiome

\section{Introduction}

The microbial diversity on this planet includes all bacteria, Archaea and most eukaryotic organisms [1,2]. Bacteria are omnipresent and the microbial diversity and abundance is very much determined by the biogeographical habitat (e.g., aquatic, terrestrial, atmospheric and living organisms) that is colonized. Bacterial activity can hence invariably affect the environment that is occupied [1].

In humans, immunological tolerance and the maturation of the intestinal mucosa has been reported to begin in utero [3,4]. The intestinal tract in humans harbors a complex set of bacterial taxa that has been intimately associated with phases of health and disease over a lifetime [5,6]. Symbiotically, the intestinal tract and the residing bacterial populations comprise one of, if not the most, metabolically and immunologically active organs in the human body [7]. Intestinal bacteria perform dual roles in an effort to maintain local homeostasis. Intestinal bacteria provide the impetus to ferment non-digestible dietary fibers to produce metabolites of short-chain fatty acids (SCFAs), which enables maximal energy extraction from dietary intake and fuels gut neuro-endocrine hormones, as well as regulating immunity. The definition of prebiotics has been derived from reports that suggest polysaccharides, including inulin, oligofructose (product of inulin), fructooligosaccharides (FOS) (synthetic polysaccharide of sucrose origin), and galactose- and xylose-containing oligosaccharides yield bifidogenic health effects in the presence of intestinal bacteria [8]. Therefore the current perception of prebiotics indeed refers to those compounds categorized as non-digestible food ingredients or substances (Figure 1), which 
pass undigested through the proximal part of the intestine (small bowel) and stimulate the growth and activity of health-promoting commensal bacteria that almost intuitively colonize the large bowel [9]. In addition to the bifidogenic effect the evidence from human studies reports that the impact of prebiotic supplementation on healthy physiological function is very much relevant to inducing satiety, increase breath-hydrogen excretion, and modulate intestinal peptides involved in appetite regulation [10].

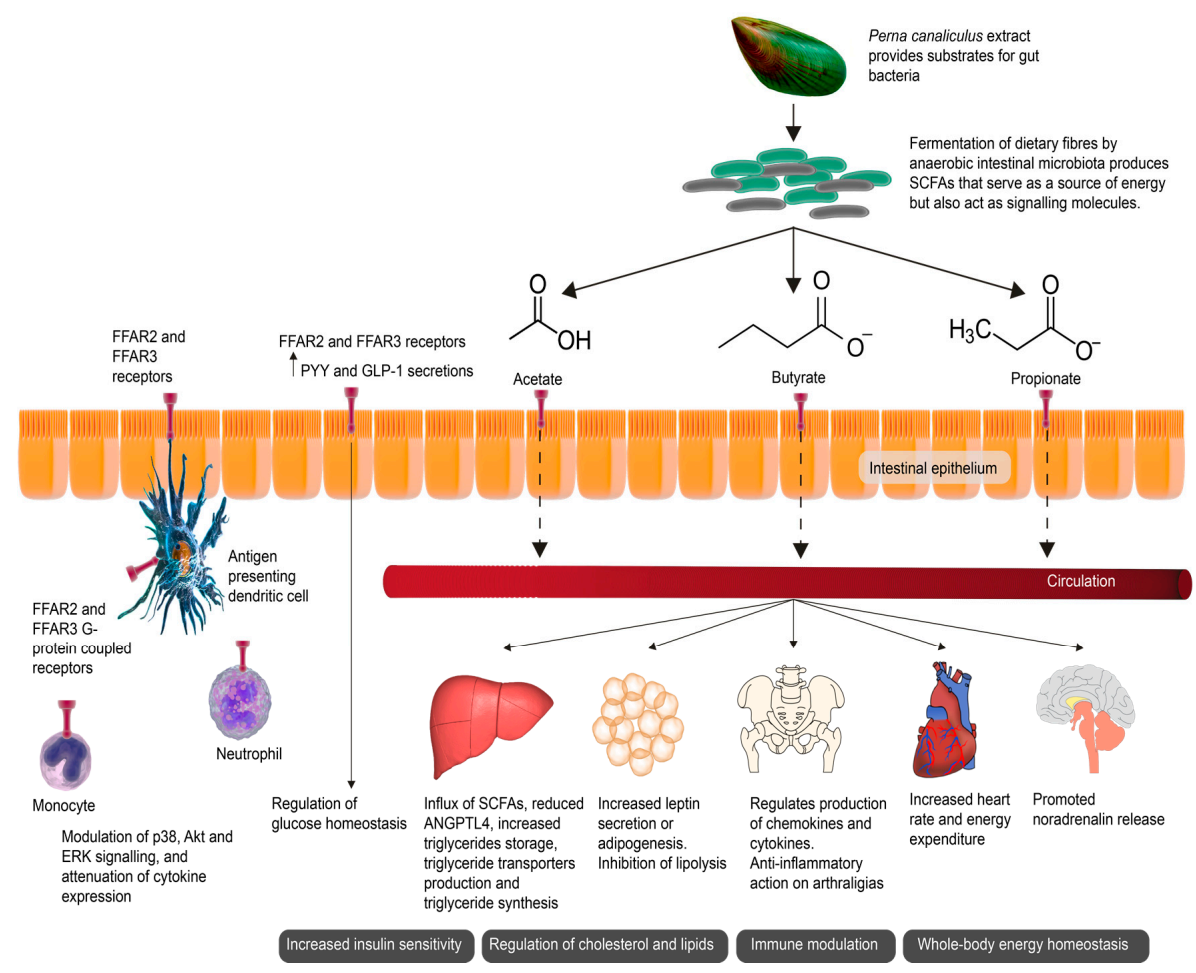

Figure 1. Short-chain fatty acids (SCFAs) as signaling molecules affected end-organ health. The green-lipped mussel (GLM) promotes anaerobic intestinal bacteria capable of producing SCFAs through the fermentation of dietary fibers. SCFAs serve as a source of energy for epithelial cells but also act as signaling molecules. SCFAs activate various receptors including the G-protein-coupled receptors Free Fatty Acid Receptors 2 and 3 (FFAR2 and FFAR3), expressed in the intestinal mucosa and on various immune cells. The activation of FFAR2 and FFAR3 stimulate the release of glucagon-like peptide-1 (GLP-1) and gut hormone peptide YY (PYY) in the intestine, improving insulin secretion. Hepatic uptake of SCFAs is associated with a decrease in angiopoietin-like 4 (ANGPTL4). ANGPTL4 regulates the uptake of triglycerides in adipocytes by inhibiting circulating lipoprotein lipase, thus promoting lipid clearance. The activation of FFAR2 and FFAR3 also promotes the release of noradrenalin, increasing the heart rate and energy expenditure, and further helping to maintain whole-body homeostasis $[11,12]$.

Bacteria residing in the intestinal tract have a potent ability to ferment otherwise indigestible complex dietary fibers into short-chain fatty acids (SCFAs) [13]. Clinical and experimental data has supported the benefits of SCFA production, with studies reporting that the gut microbiota of healthy volunteers differs from subjects with chronic diseases or infections and that significant depletions in bacterial species associated with SCFA production correlates with increases in opportunistic pathogens [14]. Whilst the metabolism of $P$. canaliculus by commensal bacteria is yet to be explored extensively, in vitro data has demonstrated their capacity to ferment and metabolize a common anti-arthritic medication, D-glucosamine [15-17]. By modifying the bioactive components of food, the intestinal microbiota can influence the exposure to nutrients that have health or disease modifying potential [17]. P. canaliculus has been demonstrated to indirectly target the intestinal microbiota and in part influence intestinal bacterial biodiversity, growth and metabolic activity [17]. 


\section{Intestinal Bacterial Cohort}

The genera of bacteria that are consistently reported as key for producing and maintaining health-promoting activities in the prebiotic literature are largely limited to the Lactobacillus and Bifidobacterium genera. However, other bacterial groups that were once considered responsible for producing unfavorable health outcomes in the intestines, such as Bacteroides and Clostridia, have been shown to be associated with beneficial physiological effects following extensive research with prebiotics. These findings have led an enhanced appreciation of the capacity of the intestinal microbial cohort as a significant therapeutic target in various pathophysiological contexts $[14,18,19]$.

Harboring a biodiverse abundance of bacteria, the intestinal microbiota is critical in shaping host health (32). Functioning as a protective barrier against pathogen translocation and preventing overgrowth of opportunistic bacteria, the intestinal microbiome can trigger deleterious host health effects as a consequence of dysbiosis [20]. The intestinal microbial cohort is very much dependent on the provision of viable substrates so that the bacteria can generate an array of metabolites such as vitamins and organic acids (i.e., branched-chain fatty acids and short-chain fatty acids) that can beneficially impact local and end-organ sites by maintaining homeostasis [21]. Homeostatic balance, characterized by a diverse and balanced microbiota, can be disrupted in the intestines, inducing pathological imbalances that are increasingly linked to the progression of metabolic disorders such as obesity and metabolic syndrome [20]; immune-meditated pathologies such as Clostridium difficile and Campylobacter jejuni infections; large bowel and liver cancers; inflammatory bowel diseases; cardiovascular disease; malnutrition; chronic kidney disease; autoimmune arthritis; multiple sclerosis, Parkinson's disease; mood disorders; and food/environmental allergies.

Dysbiosis, a gut barrier abnormality of the intestinal epithelia, may also play a central role in nutraceutical efficacy to help ameliorate these conditions. Modulation of the intestinal microbiota is a potential novel therapeutic modality to improve the health outcomes of such diseases and conditions. Immunomodulation, by which an immune response is modified in either a positive or negative manner through the administration of a pharmacological agent or other compound that could be classed as a prebiotic, is a quality that can be harnessed from various naturally occurring marine invertebrates such as the green-lipped mussel [22].

\section{Bioactive Molecules and Compounds from Green-Lipped Mussel}

The species of Perna canaliculus is a member of the Bivalvia class from the Mollusca phylum within the Mytilidae family. Paleontological data that dates back to 60 million years ago to the Eocene period documents the existence of the Perna genus [23]. Containing both green and brown mussel species, the genus is located primarily in the marina of the Southern Hemisphere, but have also been discovered on the northern coastal regions of South America and North Africa [23]. There are three species within the Perna genus that are dispersed across the globe: the P. viridis species (Asian green mussel) in Indo-Pacific region; the P. perna (brown or rock mussel) species from Atlantic regions, and; the P. canaliculus species, limited to the marine regions of New Zealand, which has been sustainably farmed for commercial purposes since the early 1970s [23]. A number of bioactive compounds from the Mytilus and Perna genuses are found within the P. canaliculus species extract, which is emerging as the most carefully and intensely investigated compound for medicinal and therapeutic effects. $P$. canaliculus has been utilized in the design of commercial therapeutic agents of arthralgia in humans and animals alike. Current studies investigating the therapeutic efficacy of P. canaliculus have only produced low-level evidence, however, an indication remains that green-lipped mussels (GLMs) have therapeutic potential as adjunctive agents for rheumatoid arthritis (RA) [22], osteoarthritis (OA) [24,25] asthma [26] and intestinal complaints [27].

Clinical and experimental data has shown various mussel species possess anti-oxidant, anti-hypertensive, anti-bacterial, anti-thrombin and anti-coagulant properties derived from their proteins, peptides and amino-acid constituents. 
Pernin remains the only bioactive protein that has been found in the cell-free hemolymph of the P. canaliculus extract. Composed of close to 500 amino acids, pernin is an aggregating, non-pigmented, glycosylated protein extract. With a particularly high concentration of histidine and aspartic acid residues, pernin is a serine protease inhibitor. However, pernin only shows a weak level of anti-thrombin activity [28]. The homogenized meat of a whole mussel contains approximately $0.2 \mathrm{mg}$ of pernin per mussel [28]. Owing to the high proportion of pernin in the hemolymph, it has been suggested that the protein must therefore be responsible for important functions in the mussel [28]. Pernin may represent an otherwise unclassified category of bivalve proteins with a distinctive structure, origin and function [28]. M. edulis has also been reported to contain another anti-coagulant peptide [29]. $P$. canaliculus supplementation has not been associated with significant side effects or allergies following its use and administration in numerous clinical studies [30]. An extremely rare adverse effect of non-granulomatous cholestatic hepatitis was associated with P. canaliculus extract consumption [30], with one of the two patients who reported this complication having a pre-existing hepatic disorder [31].

\subsection{Mechanism of Intestinal Actions}

The anti-inflammatory effect of Perna has been attributed to a number of factors, one of which being its ability to reduce the biosynthesis of pro-inflammatory prostaglandins [22]. It has been suggested that $P$. canaliculus contains active inhibitors of prostaglandins, as demonstrated by an increase in the gestation period of rats following the administration of $P$. canaliculus extract powder [32]. Clinical studies have yet to be completed assessing the therapeutic efficacy of mussel proteins and peptide fractions in humans. Reviews have suggested that the intestinal microbiota may be involved in the down-regulation of intestinal mucosal inflammation and, as such, the administration of compounds like P. canaliculus to manage symptoms of inflammatory conditions like OA and potentially RA are viable adjunctive therapies [33].

\subsection{Immunomodulation}

Early studies with murinae models have shown that the lipid-rich fraction of the GLM exhibits synergistic anti-inflammatory properties that are characteristic of immunomodulation when administered in combination with oral non-steroidal anti-inflammatory drugs (NSAIDs) and analgesic medications including prednisone, pentoxifylline or meloxicam [34,35]. Following tandem delivery, paw swelling was significantly reduced in rats with adjuvant-induced arthritis and zymosan-induced paw inflammation [35]. In fact, the symptom relief from tandem therapies was more effective than that of NSAID therapy alone [35]. P. canaliculus extract powder has shown synergistic and anti-inflammatory activity when administered in combination with other NSAIDs. Experimental data has demonstrated that the stabilized whole extract powder of $P$. canaliculus decreases the severity and episodes of intestinal barrier damage in rat models $[33,34]$. The anti-inflammatory activity of acetylsalicyclic acid and indomethacin is further supported by reports that lipid and whole extract powders affect gastroprotective effects [36].

Experimental evidence from an animal model of inflammatory bowel disease (IBD) has suggested that the lipid-rich fraction of the supercritical extract of P. canaliculus may exert gastroprotective effects to treat colonic damage [27], as results reported improvement in intestinal inflammation markers and intestinal morphology in chemotherapy-induced mucositis in an animal models [27]. Studies conducted recently in humans reported that the administration of a whole P. canaliculus extract may support intestinal function and potentially protect the intestinal tract when delivered in conjunction with analgesic and anti-inflammatory medications in OA patients $[17,25]$.

Approximately $70 \%$ of an extract of whole mussel P. canaliculus is protein. Exhibiting both humoral and cellular immunemodulating effects, previous investigations have demonstrated the strong anti-inflammatory profile of Perna [22]. Furthermore, the anti-inflammatory potential of Perna has been shown to be as effective as NSAIDs in its ability to reduce inflammation in murine models of carrageenan-induced footpad edema [22]. Animal and in vitro model data indicates that fractionated 
extracts of whole extract powder derive their anti-inflammatory and immunomodulating properties from an active agent that is predominantly a protein moiety or an actual protein macromolecule $[37,38]$. Unfortunately, high-level evidence for the bioactive high molecular weight protein is lacking and requires further analysis $[37,38]$. Furthermore, a recent study suggests that marine compounds such as the red seaweed Chondrus crispus presents evidence that when orally administered may act as a prebiotic [39]. The prebiotic effects suggested were consistent with influencing the composition of the intestinal microbial communities, improvement of intestinal health and immune modulation in the animals that were supplemented with Chondrus crispus.

The mechanism of anti-inflammatory activity and immunomodulating properties of $P$. canaliculus has been hypothesized to be a result of the inhibition of the production of pro-inflammatory cytokines [22]. Blocking arachidonic metabolism through cyclooxygenase (COX) and lipoxygenase pathways, $P$. canaliculus can efficiently block the action of COX-1 and COX-2 enzymes via a dose-dependent mechanism. It is this blockage in COX pathways that is linked with reduced levels of multiple pro-inflammatory cytokines, including interleukin (IL) 1, IL-2, Il-6 and tumor necrosis factor alpha (TNF-alpha) [22]. Regulating the pro-inflammatory network, TNF-alpha plays a disease-promoting role in RA. Moreover, Perna is perhaps a safer therapeutic modality than NSAIDs in light of the preferential blockage of the pro-inflammatory COX-2 enzyme over the physiologically superior COX-1 enzyme. With numerous inflammatory and autoimmune responses triggered by abnormally high levels of systemic TNF-alpha, compromising or disrupting their production with the use of naturally occurring organisms or compounds such as M. edulis and P. canaliculus is a viable approach [22]. Lyprinol contains the oil of P. canaliculus and displays anti-inflammatory effects in vivo and in vitro [40]. Table 1 details randomized clinical trials that have investigated the effect of P. canaliculus supplementation in the treatment of arthritic diseases.

\subsection{Anti-Microbial Activities}

Anti-microbial peptides (AMPs) have been detected in the hemolymph of mussels and form the basis of their innate immunodefense system. Providing protection against bacterial, fungal and viral invasions, these mussel-origin AMPs are of particular interest and specifically those derived from the Blue mussel (Mytilus edulis) and the Mediterranean (or Blue) mussel (Mytilis galloprovincialis) species. The M. edulis species has been shown to possess numerous cysteine-rich peptides that impart potent bactericidal (i.e., against Gram-positive organisms, e.g., Enterococcus faecalis, Staphylococcus aureus and Gram-negative bacteria, e.g., Escherichia coli bacteria) and anti-fungal (i.e., Neurospora crassa and Fusarium culmorum) functionality [41]. The AMPs identified have been classified as isoforms of the peptide families of defensins, mytimycin and mytilin with big defensins [38,41]. The crustacean hemolymph, specifically of crab origin, possesses a range of AMPs that act as endogenous antibiotics, as well as participating in pro-inflammatory activity, wound repair and regulating adaptive immunity responses [33]. These findings of the potency of whole mussel extract powder has provided the impetus for integrating marine peptides into novel pharmaceutical developments [42].

\subsection{Cardiovascular Effects}

The fermented M. edulis possesses angiotensin I converting enzyme (ACE) inhibiting peptides that exert anti-hypertensive effects, as reported by in vivo rat model data [43].

Conversely, the lipid fraction of Perna has been extensively investigated. Associated with potent anti-inflammatory activity, M. edulis and P. canaliculus, like other marine organisms, are naturally low in dietary cholesterol [44]. However, it is their possession of cholesterol-lowering phytosterols and $\boldsymbol{\omega}-3$ PUFAs that separate these marine organisms from the naturally omega-6 ( $\boldsymbol{\omega}-6)$ rich terrestrial organisms [45] and impart therapeutic properties. The $\boldsymbol{\omega}$-3 PUFA portion has been suggested to be responsible for helping to reduce risk factors associated with cardiovascular disease, as well as helping to relieve symptoms of inflammatory disorders like OA [44]. 
Table 1. Clinical trials with Perna canaliculus extract for the treatment of arthritic diseases.

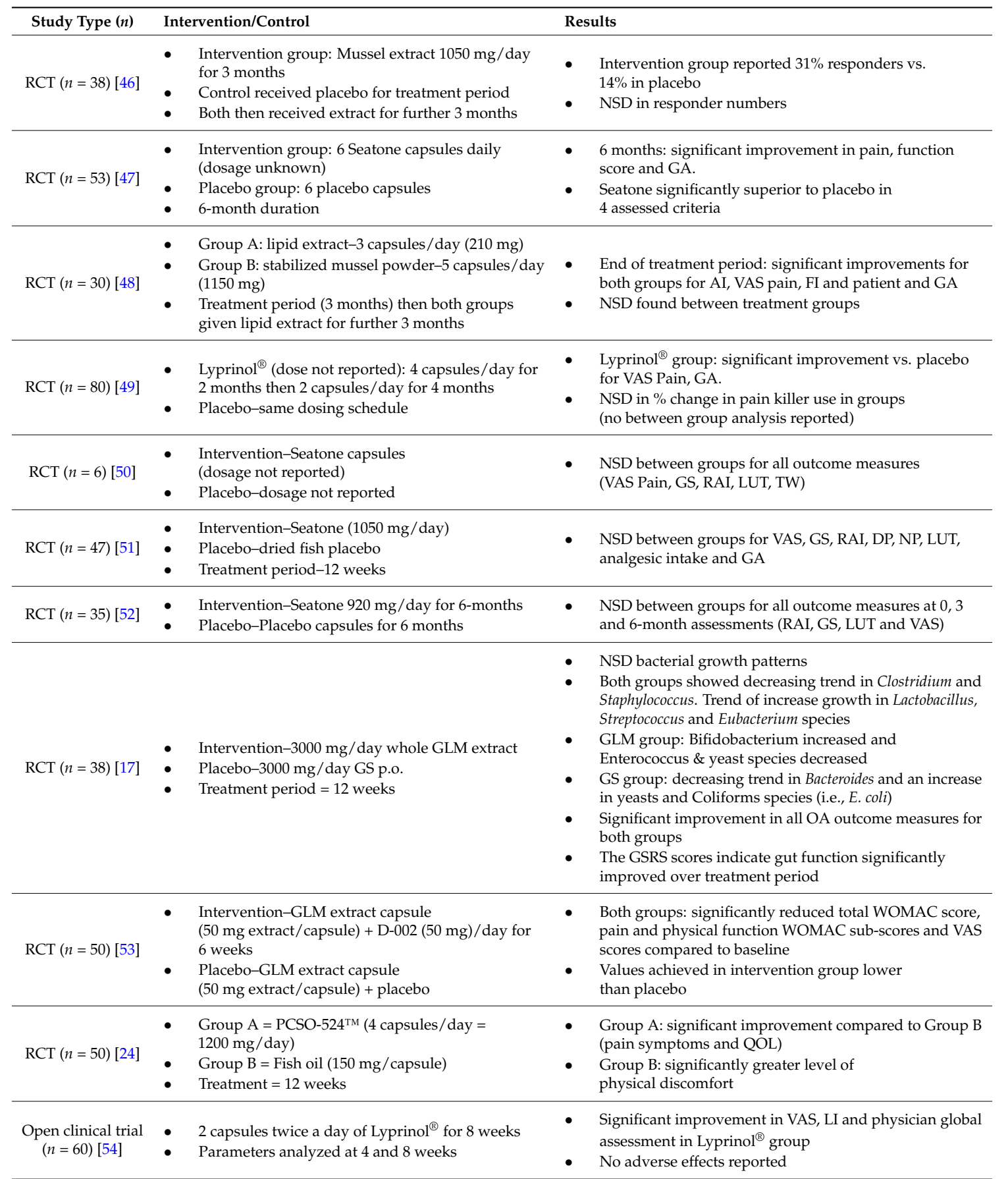

RCT: randomised controlled trial, NSD: not significant difference; AI: articular index; VAS: visual analogue scale; FI: functional index; RAI: Ritchie articular index of joint tenderness; LUT: morning joint stiffness or limbering-up time; GS: grip strength; TW: time to walk set distance or maximum walking distance; DP: severity of day-time pain; NP: severity of night-time pain; GA: patient and physician's global assessment; QOL: quality of life.

\section{The Microbiome and Omega-3 Fatty Acids}

\subsection{Changes in the Intestinal Microbiome}

Changes in the microbiota profiles and gut functionality were observed in patients diagnosed with OA and subsequently treated with a Perna canaliculus meat freeze-dried powder. The most significant change was a decrease in the Clostridia spp. This study suggests that the mussel meat powder may serve to control metabolic and immunity activity of the intestinal microbiome. Clostridia, previously 
established as a potent modulator of Th17 and CD4+ regulatory cells, correlates with inflammation and Gastrointestinal Symptom Rating Scale (GSRS) scores and OA symptoms [17].

Several animal and human studies have shown that a diet rich in $\boldsymbol{\omega}$-3 PUFAs strongly alters the microbiome composition, although one study found that while $\omega-3$ PUFAs had a significant effect on insulin sensitivity and hsCRP, they had no effect on gut microbiota in a study of 60 overweight adults [55]. A diet rich in the fish fatty acids EPA and DHA for 15 days decreased Helicobacter, Clostridiales bacterium, Sphingomonadales bacterium and Pseudomonas species Firmicutes in mice [56], while a diet rich in sardines for six months (100 g sardines providing $3 \mathrm{~g}$ EPA and DHA) was shown in 35 drug-naïve patients with type 2 diabetes to be associated with a shift in the intestinal microbiome. Both the fish and the standard diabetes diets decreased phylum Firmicutes $(p=0.04)$ and increased E. coli concentrations $(p=0.01)$ compared to baseline. However, only the fish diet was associated with a decreased in the ratios of Firmicutes to Bacteroidetes $(p=0.04)$ and an increase in the ratio of Bacteroides to Prevotella $(p=0.04)$ compared to baseline [57].

The ratio of pro-inflammatory $\boldsymbol{\omega}-6$ to anti-inflammatory $\boldsymbol{\omega}-3$ PUFAs is also important for gut health. High intakes of dietary fat, including palm oil, olive oil, safflower oil or linseed/fish oil for 16 weeks was shown by high-throughput 16S rRNA sequencing to significantly alter the microbiome of C57BL/6J mice. The linseed/fish oil diet triggered significant growth in the genus level of Bifidobacterium compared to mice fed a low-fat high-maize starch diet $(p<0.05)$ [58]. Intestinal dysbiosis and low-grade systemic inflammation was reported to have been induced in the group of mice that were allocated to and fed a diet high in $\boldsymbol{\omega}-6$ PUFAs. Mice fed a diet supplemented with $\boldsymbol{\omega}-3$ PUFAs showed changes in their intestinal bacterial profile composition, which led to a decrease in lipopolysaccharide (LPS) and therefore enhanced gut barrier integrity. This chain of events ultimately reduced levels of metabolic endotoxemia and inflammatory activity [59]. A diet high in $\boldsymbol{\omega}-6$ PUFAs from corn oil was further shown in a rodent model of colitis to increase the level of Enterobacteriaceae, Segmented Filamentous Bacteria and Clostridia spp. which aggravated and disturbed the intestinal barrier, immune cell proliferation, the expression of prostaglandin E2 and the passage of $C$. rodentium across the intestinal mucosae. Adding $\boldsymbol{\omega}$-3 PUFAs reversed these inflammatory-inducing bacteria and enriched the level of Lactobacillus and Bifidobacterium species [60].

\subsection{SCFAs as Signaling Molecules for End-Organ Health}

Fermentation of dietary fibers by anaerobic intestinal microbiota produces short-chain fatty acids (SCFAs). Evidence from aforementioned studies of $\omega-3$ PUFAs from a variety of sources, including fish and P. canaliculus, suggest that certain oils may have a beneficial effect on the microbiome by triggering the growth of certain intestinal bacterial species, which may contribute to the microbiome's ability to produce SCFAs. Primarily serving as an energy source, SCFAs also act as signaling molecules (Figure 1) [17]. Clinical data from OA patients treated with a P. canaliculus containing GLM extract reported significant improvement in GSRS scores, supporting the hypothesis that the metabolism of P. canaliculus containing GLM compounds may generate the production of SCFA metabolites. This hypothesis provides a plausible mechanism of action of P. canaliculus as a therapeutic nutraceutical [17]. Further studies have reported a gastroprotective effect of GLM, with intestinal dysfunction significantly improved in GLM-treated subjects further suggesting that $P$. canaliculus may play an important role in intestinal sequelae and intestinal barrier maintenance [25]. From the rudimentary analysis of fecal samples by Coulson et al. [17], the study showed that Bacteroides (a genus of Gram-negative, obligate anaerobic bacteria) as a group were increased at the end of the P. canaliculus supplementation period, indicating that $P$. canaliculus possibly increased SCFA-producing intestinal bacteria. The majority of SCFAs produced are taken up in the colon with only $5-10 \%$ secreted via the feces. Only a small percentage is absorbed by passive transfusion, with the majority absorbed by monocarboxylate transporters (MCT), SLC5A8 (sodium coupled transporters (SMCT)), as well as the G-protein-coupled receptors Free Fatty Acid Receptors 2 and 3 (FFAR2 and FFAR3). The SCFAs of acetate and propionate have been found to primarily activate FFAR2, whereas propionate and 
butyrate are responsible for the activation of FFAR3. A range of immune cells have been shown to express FFAR2 and exert immunomodulating effects. The activation of FFAR2 and FFAR3 stimulates glucagon-like peptide-1 (GLP-1) secretion and gut hormone peptide YY (PYY) in the intestine, resulting in improved insulin release. SCFAs produced by fermentation of dietary fibres by a healthy microbiota thus help manage blood glucose levels. Lack of dietary fibre is conversely related to an increased risk of developing insulin resistance and eventual onset of type 2 diabetes mellitus. FFAR2 and FFAR3 also helps maintain whole-body energy homeostasis by regulating leptin, adipogenesis, fat accumulation and lipolysis in adipose tissue as well as regulating hepatic cholesterol synthesis and triglyceride storage. Hepatic uptake of SCFAs is also associated with a decrease in angiopoietin-like 4 (ANGPTL4). ANGPTL4 regulates the uptake of triglycerides in adipocytes by inhibiting circulating lipoprotein lipase thus promoting lipid clearance. Activation of FFAR2 and FFAR3 also promote the release of noradrenalin, increasing heart rate and energy expenditure, and further helping to maintain whole-body homeostasis [11,12].

\subsection{Gut Synthesis of Butyrate}

A majority of the butyrate produced in the intestinal tract is posited to originate from carbohydrates. However, a subset of specialized intestinal bacteria has been identified that facilitates the conversion of lactate and acetate to butyrate. Intestinimonas strain AF211, a commensal bacterium, has been shown to convert lysine into butyrate and acetate, suggesting that proteins have the capacity to provide a source of butyrate in the colon [61]. However, only $5 \%$ of gut SCFAs are derived from lysine conversion [62]. SCFAs in the gut are in a state of flux. Numerous bacterial species are involved in the production and interconversion of SCFAs. A large group including Bacteroides, Proteobacteria, Bifidobacteria, Clostridia, and Eubacteria produce acetate. E. rectale and Roseburia spp. can utilize actetate to produce butyrate. Butyrate can also be converted back to actatate by sulfate- or nitrate-reducing acetogenic bacteria [63].

Marine lipids may also influence the microbiome and end organs by enhancing butyrate-producing bacteria. Animals with early life stress, induced by maternal separation, have been shown to develop dysbiosis characterized by a decreased ratio of Bacteroidetes to Firmicutes and the induction of inflammatory cytokines in plasma. Long-term administration of EPA and DHA reversed this shift. Maternal separation induced Akkermansia spp., a bacteria associated with degradation of mucus, and microbial translocation across the mucosa, exacerbating gut inflammation [64]. Akkermansia spp. is also a butyrate-producing bacterium. A diet containing $600 \mathrm{mg} \omega-3$ PUFAs daily for 14 days has been shown in a 45 -year-old male to increase butyrate-producing bacteria Roseburia intestinalis and Eubacterium rectale, which became the predominant species. The study found that $\boldsymbol{\omega}$-3 PUFAs for two weeks were associated with increases in Eubacterium, Roseburia, Anaerostipes, Coprococcus, Subdoligranulum, and Pseudobutyrivibrio, which are genera associated with butyrate production. These changes were reversed after a 14-day washout period [65].

\section{Discussion}

Nutraceutical supplements, such as GLMs and glucosamine sulfate (GS), when administered orally, are known to be metabolized by the intestinal microbiota $[7,33]$. While the metabolism of GLM extract is yet to be investigated comprehensively, preliminary in vitro studies have confirmed that GS extract is fermented and metabolized by commensal intestinal bacteria $[15,16,66]$.

Understanding the distribution of the intestinal microbiome can help further progress effective adjunctive treatments that can abrogate unwanted side effects of medical therapies. Mucositis and $\boldsymbol{\omega}-3$ PUFAs is such an example. Fish fatty acids such as EPA and DHA from a lipid-rich extract of $P$. canaliculus and a combination of the two fatty acids have been investigated in animal models of 5-FU-induced mucositis. DHA was reported as more beneficial than EPA with the combination having the best effects. Fish oils and a lipid-rich extract from P. canaliculus have also been shown to ameliorate the toxic effects of 5-FU on the intestines. Pretreatment with DHA in conjunction with 
protein supplementation has been shown in rats to reduce apoptosis of intestinal cells following 5-FU treatment [67]. $\boldsymbol{\omega}$-3 PUFAs may enhance the efficacy while reducing adverse effects of cytotoxic drugs. 5-FU in combination with fish oils has been shown to increase the survival rate in carcinogen-treated animals. Synergism of 5-FU and fish oil was also reflected in significant inhibition in tumor growth in a model of colon cancer. Fish oils also ameliorated 5-FU-induced toxicity as substantiated by a marked improvement in the structural and functional alterations of various organs [68]. In a study comparing Lyprinol with fish oil and olive oil, pretreatment with $\omega-3$ PUFAs from both fish oils and P. canaliculus (Lyprinol) and olive oil for five days decreased 5-FU-induced mucositis in rats. The weight of the small intestine was significantly greater in animals receiving fish oils from and $P$. canaliculus compared to controls $(p<0.05)$. Lyprinol was also associated with less severe histological damage with the intestines having longer crypts and increased proliferation in the midsection of the small intestine compared to controls $(p<0.05)$, although it was unable to prevent 5-FU-induced weight loss, decreased feed intake and the weight of thymus and spleen [69]. The synergistic effect of DHA and EPA was also demonstrated in a mouse study where pretreatment was shown to reduce weight loss and preserve intestinal mucosa and integrity following 5-FU injection. The diet was associated with longer villi compared to controls. The diet also reduced inflammatory cytokine activation and expression, and upregulated anti-apoptotic genes [70].

Clinical and experimental data both suggest that $\boldsymbol{\omega}-3$ PUFAs may trigger a beneficial effect in metabolic syndrome-related conditions. In response to a diet enriched with $\boldsymbol{\omega}-3$ PUFAs, the intestinal microbiota is characterized by a shift in the composition and abundance of butyrate-producing bacterial species [65]. Such a shift in the microbial configuration provides a possible explanation as to how $\boldsymbol{\omega}-3$ PUFA supplementation ameliorates acute and chronic diseases associated with intestinal epithelial dysbiosis. With intestinal epithelial dysbiosis identified as a trigger for metabolic syndrome and the associated complications that ensue, the intestinal microbiota presents as a major target in the management and possible treatment of such pathologies. As the hepatic expression of the metabolic syndrome, non-alcoholic fatty liver disease (NAFLD), may present as another therapeutic target for marine-derived $\boldsymbol{\omega}$-3 PUFA supplementation [71]. Studies have shown that various supplements rich in $\omega-3$ PUFAs reversed hepatic lipid accumulation and inflammatory markers in subjects with pre-existing hepatic steatosis. The results of such studies are underpinned by the hypothesis that $\boldsymbol{\omega}$-3 PUFAs alter the intestinal microbiome while concurrently regulating hepatic lipid metabolism [72]. Although data implicates configurational changes in the intestinal microbiome profile in the manifestation of chronic and acute adverse health effects, a requisite for prospective studies remains to establish definitive mechanisms of actions and pathogenesis.

\section{Conclusions}

Understanding how the bioactive compounds derived from P. canaliculus interact and communicate with the microbiome populating the intestinal tract may help to facilitate and guide the design of novel therapeutic agents to manage intra-intestinal and extra-intestinal inflammations [17]. An altered intestinal microbial profile is purported to be a significant contributor to the therapeutic efficacy of GLMs and other nutraceutical supplements [17]. Intestinal epithelial dysbiosis is implicated in the onset and maintenance of acute and chronic diseases, with $\omega-3$ PUFA rich P. canaliculus hypothesized to proliferate the growth of microbial species linked with SCFA-production. This shift in the intestinal microbial composition and increased production of SCFA, particularly butyrate, is associated with anti-inflammatory, anti-microbial and immunomodulatory effects. As such, in vitro and RCTs have shown P. canaliculus and other marine-derived omega-3 fatty acid rich supplements as potential therapeutic agents for arthritic diseases, metabolic syndrome and associated complications, as well as chemotherapy-induced mucositis. However, it is important to note that the various RCTs that have been conducted to date using commercial preparations containing P. canaliculus vary greatly [73] and, as such, further investigations into the active substance composition would be beneficial to confirm their physiological effects. 
Author Contributions: E.T.S. and L.V. conception and design of commentary/review. E.T.S., L.V., S.H. and M.T. were involved in the preparation of the manuscript. E.S. prepared Table 1. M.T. designed Figure 1. E.T.S., L.V., M.T. and S.H. read, amended, and approved the final version of the manuscript.

Conflicts of Interest: L.V. has received National Institute of Complementary Medicine and National Health and Medical Research Council of Australia competitive funding and Industry support for research into bio-compounds and probiotics. E.T.S., L.V., M.T. and S.H. participate in research on probiotics in Medlab Clinical's research laboratory facility in Sydney, Australia.

\section{References}

1. Schloss, P.D.; Girard, R.A.; Martin, T.; Edwards, J.; Thrash, J.C. Status of the archaeal and bacterial census: An update. mBio 2016, 7, e00201-16. [CrossRef] [PubMed]

2. Amann, R.; Rossello-Mora, R. After all, only millions? mBio 2016, 7, e00999-16. [CrossRef] [PubMed]

3. Jimenez, E.; Fernandez, L.; Marin, M.L.; Martin, R.; Odriozola, J.M.; Nueno-Palop, C.; Narbad, A.; Olivares, M.; Xaus, J.; Rodriguez, J.M. Isolation of commensal bacteria from umbilical cord blood of healthy neonates born by cesarean section. Curr. Microbiol. 2005, 51, 270-274. [CrossRef] [PubMed]

4. Aagaard, K.; Ma, J.; Antony, K.M.; Ganu, R.; Petrosino, J.; Versalovic, J. The placenta harbors a unique microbiome. Sci. Transl. Med. 2014, 6, 237ra65. [CrossRef] [PubMed]

5. Trosvik, P.; de Muinck, E.J. Ecology of bacteria in the human gastrointestinal tract-Identification of keystone and foundation taxa. Microbiome 2015, 3, 44. [CrossRef] [PubMed]

6. Vitetta, L.; Hall, S.; Linnane, A.W. Live probiotic cultures and the gastrointestinal tract: Symbiotic preservation of tolerance whilst attenuating pathogenicity. Front. Cell. Infect. Microbiol. 2014, 4, 143. [CrossRef] [PubMed]

7. $\quad$ Egert, M.; de Graaf, A.A.; Smidt, H.; de Vos, W.M.; Venema, K. Beyond diversity: Functional microbiomics of the human colon. Trends Microbiol. 2006, 14, 86-91. [CrossRef] [PubMed]

8. Hutkins, R.W.; Krumbeck, J.A.; Bindels, L.B.; Cani, P.D.; Fahey, G., Jr.; Goh, Y.J.; Hamaker, B.; Martens, E.C.; Mills, D.A.; Rastal, R.A.; et al. Prebiotics: Why definitions matter. Curr. Opin. Biotechnol. 2016, 37, 1-7. [CrossRef] [PubMed]

9. Bindels, L.B.; Delzenne, N.M.; Cani, P.D.; Walter, J. Towards a more comprehensive concept for prebiotics. Nat. Rev. Gastroenterol. Hepatol. 2015, 12, 303-310. [CrossRef] [PubMed]

10. Cani, P.D.; Lecourt, E.; Dewulf, E.M.; Sohet, F.M.; Pachikian, B.D.; Naslain, D.; de Backer, F.; Neyrinck, A.M.; Delzenne, N.M. Gut microbiota fermentation of prebiotics increases satietogenic and incretin gut peptide production with consequences for appetite sensation and glucose response after a meal. Am. J. Clin. Nutr. 2009, 90, 1236-1243. [CrossRef] [PubMed]

11. Yoo, J.Y.; Kim, S.S. Probiotics and prebiotics: Present status and future perspectives on metabolic disorders. Nutrients 2016, 8, 173. [CrossRef] [PubMed]

12. Schilderink, R.; Verseijden, C.; de Jonge, W.J. Dietary inhibitors of histone deacetylases in intestinal immunity and homeostasis. Front. Immunol. 2013, 4, 226. [CrossRef] [PubMed]

13. Zhao, J.; Nian, L.; Kwok, L.Y.; Sun, T.; Zhao, J. Reduction in fecal microbiota diversity and short-chain fatty acid producers in methicillin-resistant staphylococcus aureus infected individuals as revealed by pacbio single molecule, real-time sequencing technology. Eur. J. Clin. Microbiol. Infect. Dis. 2017. [CrossRef] [PubMed]

14. Roberfroid, M.; Gibson, G.R.; Hoyles, L.; McCartney, A.L.; Rastall, R.; Rowland, I.; Wolvers, D.; Watzl, B.; Szajewska, H.; Stahl, B.; et al. Prebiotic effects: Metabolic and health benefits. Br. J. Nutr. 2010, 104, S1-S63. [CrossRef] [PubMed]

15. Foley, S.; Stolarczyk, E.; Mouni, F.; Brassart, C.; Vidal, O.; Aissi, E.; Bouquelet, S.; Krzewinski, F. Characterisation of glutamine fructose-6-phosphate amidotransferase (ec 2.6.1.16) and n-acetylglucosamine metabolism in bifidobacterium. Arch. Microbiol. 2008, 189, 157-167. [CrossRef] [PubMed]

16. Koser, S.A.; Tribby, I.; Stuedell, J.T. Glucosamine utilization by some lactic acid bacteria. J. Infect. Dis. 1961, 108, 324-332. [CrossRef] [PubMed]

17. Coulson, S.; Butt, H.; Vecchio, P.; Gramotnev, H.; Vitetta, L. Green-lipped mussel extract (perna canaliculus) and glucosamine sulphate in patients with knee osteoarthritis: Therapeutic efficacy and effects on gastrointestinal microbiota profiles. Inflammopharmacology 2013, 21, 79-90. [CrossRef] [PubMed] 
18. Rastall, R.A.; Gibson, G.R. Recent developments in prebiotics to selectively impact beneficial microbes and promote intestinal health. Curr. Opin. Biotechnol. 2015, 32, 42-46. [CrossRef] [PubMed]

19. Kellow, N.J.; Coughlan, M.T.; Reid, C.M. Metabolic benefits of dietary prebiotics in human subjects: A systematic review of randomised controlled trials. Br. J. Nutr. 2014, 111, 1147-1161. [CrossRef] [PubMed]

20. Adamu, B.O.; Lawley, T.D. Bacteriotherapy for the treatment of intestinal dysbiosis caused by clostridium difficile infection. Curr. Opin. Microbiol. 2013, 16, 596-601. [CrossRef] [PubMed]

21. Vitetta, L.; Hall, S.; Coulson, S. Metabolic interactions in the gastrointestinal tract (git): Host, commensal, probiotics, and bacteriophage influences. Microorganisms 2015, 3, 913-932. [CrossRef] [PubMed]

22. Lawson, B.R.; Belkowski, S.M.; Whitesides, J.F.; Davis, P.; Lawson, J.W. Immunomodulation of murine collagen-induced arthritis by $\mathrm{n}, \mathrm{n}$-dimethylglycine and a preparation of perna canaliculus. BMC Complement. Altern. Med. 2007, 7, 20. [CrossRef] [PubMed]

23. Wood, A.R.; Apte, S.; MacAvoy, E.S.; Gardner, J.P. A molecular phylogeny of the marine mussel genus perna (bivalvia: Mytilidae) based on nuclear (its1\&2) and mitochondrial (coi) DNA sequences. Mol. Phylogenet. Evol. 2007, 44, 685-698. [PubMed]

24. Zawadzki, M.; Janosch, C.; Szechinski, J. Perna canaliculus lipid complex pcso-524 demonstrated pain relief for osteoarthritis patients benchmarked against fish oil, a randomized trial, without placebo control. Mar. Drugs 2013, 11, 1920-1935. [CrossRef] [PubMed]

25. Coulson, S.; Vecchio, P.; Gramotnev, H.; Vitetta, L. Green-lipped mussel (perna canaliculus) extract efficacy in knee osteoarthritis and improvement in gastrointestinal dysfunction: A pilot study. Inflammopharmacology 2012, 20, 71-76. [CrossRef] [PubMed]

26. Mickleborough, T.D.; Vaughn, C.L.; Shei, R.J.; Davis, E.M.; Wilhite, D.P. Marine lipid fraction pcso-524 (lyprinol/omega xl) of the new zealand green lipped mussel attenuates hyperpnea-induced bronchoconstriction in asthma. Respir. Med. 2013, 107, 1152-1163. [CrossRef] [PubMed]

27. Tenikoff, D.; Murphy, K.J.; Le, M.; Howe, P.R.; Howarth, G.S. Lyprinol (stabilised lipid extract of new zealand green-lipped mussel): A potential preventative treatment modality for inflammatory bowel disease. J. Gastroenterol. 2005, 40, 361-365. [CrossRef] [PubMed]

28. Scotti, P.D.; Dearing, S.C.; Greenwood, D.R.; Newcomb, R.D. Pernin: A novel, self-aggregating haemolymph protein from the new zealand green-lipped mussel, perna canaliculus (bivalvia: Mytilidae). Comp. Biochem. Physiol. B Biochem. Mol. Biol. 2001, 128, 767-779. [CrossRef]

29. Jung, W.-K.; Kim, S.-K. Isolation and characterisation of an anticoagulant oligopeptide from blue mussel, mytilus edulis. Food Chem. 2009, 117, 687-692. [CrossRef]

30. Abdulazim, A.; Hädrich, M.; Montani, M.; Semmo, N. Acute hepatitis induced by lyprinol, the lipid extract of the green-lipped mussel (perna canaliculus), in a patient with polyarthrosis. Case Rep. Hepatol. 2012, 2012, 2. [CrossRef] [PubMed]

31. Sukumaran, S.; Pittman, K.B.; Patterson, W.K.; Dickson, J.; Yeend, S.; Townsend, A.; Broadbridge, V.; Price, T.J. A phase I study to determine the safety, tolerability and maximum tolerated dose of green-lipped mussel (perna canaliculus) lipid extract, in patients with advanced prostate and breast cancer. Ann. Oncol. 2010, 21, 1089-1093. [CrossRef] [PubMed]

32. Miller, $\mathrm{T}$; $\mathrm{Wu}, \mathrm{H}$. In vivo evidence for prostaglandin inhibitory activity in new zealand green-lipped mussel extract. N. Z. Med. J. 1984, 97, 355-357. [PubMed]

33. Coulson, S.; Palacios, T.; Vitetta, L. Perna canaliculus (green-lipped mussel): Bioactive components and therapeutic evaluation for chronic health conditions. Prog. Drug Res. 2015, 70, 91-132. [PubMed]

34. Whitehouse, M.W.; Butters, D.E. Combination anti-inflammatory therapy: Synergism in rats of nsaids/corticosteroids with some herbal/animal products. Inflammopharmacology 2003, 11, 453-464. [CrossRef] [PubMed]

35. Whitehouse, M.W. Anti-tnf-alpha therapy for chronic inflammation: Reconsidering pentoxifylline as an alternative to therapeutic protein drugs. Inflammopharmacology 2004, 12, 223-227. [CrossRef] [PubMed]

36. Rainsford, K.D.; Whitehouse, M.W. Gastroprotective and anti-inflammatory properties of green lipped mussel (perna canaliculus) preparation. Arzneimittel-Forschung 1980, 30, 2128-2132. [PubMed]

37. Mani, S.; Lawson, J.W. In vitro modulation of inflammatory cytokine and igg levels by extracts of perna canaliculus. BMC Complement. Altern. Med. 2006, 6, 1. [CrossRef] [PubMed]

38. Grienke, U.; Silke, J.; Tasdemir, D. Bioactive compounds from marine mussels and their effects on human health. Food Chem. 2014, 142, 48-60. [CrossRef] [PubMed] 
39. Liu, J.; Kandasamy, S.; Zhang, J.; Kirby, C.W.; Karakach, T.; Hafting, J.; Critchley, A.T.; Evans, F.; Prithiviraj, B. Prebiotic effects of diet supplemented with the cultivated red seaweed chondrus crispus or with fructo-oligo-saccharide on host immunity, colonic microbiota and gut microbial metabolites. BMC Complement. Altern. Med. 2015, 15, 279. [CrossRef] [PubMed]

40. Wakimoto, T.; Kondo, H.; Nii, H.; Kimura, K.; Egami, Y.; Oka, Y.; Yoshida, M.; Kida, E.; Ye, Y.; Akahoshi, S.; et al. Furan fatty acid as an anti-inflammatory component from the green-lipped mussel perna canaliculus. Proc. Nat. Acad. Sci. USA 2011, 108, 17533-17537. [CrossRef] [PubMed]

41. Charlet, M.; Chernysh, S.; Philippe, H.; Hetru, C.; Hoffmann, J.A.; Bulet, P. Innate immunity. Isolation of several cysteine-rich antimicrobial peptides from the blood of a mollusc, mytilus edulis. J. Biol. Chem. 1996, 271, 21808-21813. [CrossRef] [PubMed]

42. Fredrick, W.S.; Ravichandran, S. Hemolymph proteins in marine crustaceans. Asian Pac. J. Trop. Biomed. 2012, 2, 496-502. [CrossRef]

43. Je, J.Y.; Park, P.J.; Byun, H.G.; Jung, W.K.; Kim, S.K. Angiotensin I converting enzyme (ace) inhibitory peptide derived from the sauce of fermented blue mussel, mytilus edulis. Biores. Technol. 2005, 96, 1624-1629. [CrossRef] [PubMed]

44. Murphy, K.J.; Mooney, B.D.; Mann, N.J.; Nichols, P.D.; Sinclair, A.J. Lipid, fa, and sterol composition of new zealand green lipped mussel (perna canaliculus) and tasmanian blue mussel (mytilus edulis). Lipids 2002, 37, 587-595. [CrossRef] [PubMed]

45. Naughton, J.M.; O'Dea, K.; Sinclair, A.J. Animal foods in traditional australian aboriginal diets: Polyunsaturated and low in fat. Lipids 1986, 21, 684-690. [CrossRef] [PubMed]

46. Gibson, R.G.; Gibson, S.L. Green-lipped mussel extract in arthritis. Lancet 1981, 1, 439. [CrossRef]

47. Audeval, B.; Bouchacourt, P. Double-blind trial against placebo extract of perna canaliculus (green-lipped mussel) in osteoarthritis of the knee. Gazette Med. 1986, 93, 111-116.

48. Gibson, S.L.M.; Gibson, R.G. The treatment of arthritis with a lipid extract of perna canaliculus: A randomized trial. Complement. Ther. Med. 1998, 6, 122-126. [CrossRef]

49. Lau, C.S.; Chiu, P.K.Y.; Chu, E.M.Y.; Cheng, I.Y.W.; Tang, W.M.; Man, R.Y.K.; Halpern, G.M. Treatment of knee osteoarthritis with lyprinol ${ }^{\circledR}$, lipid extract of the green-lipped mussel-A double-blind placebo-controlled study. Prog. Nutr. 2004, 6, 17-31.

50. Highton, T.C.; McArthur, A.W. Pilot study on the effect of new zealand green mussel on rheumatoid arthritis. N. Z. Med. J. 1975, 81, 261-262. [PubMed]

51. Caughey, D.E.; Grigor, R.R.; Caughey, E.B.; Young, P.; Gow, P.J.; Stewart, A.W. Perna canaliculus in the treatment of rheumatoid arthritis. Eur. J. Rheumatol. Inflamm. 1983, 6, 197-200. [PubMed]

52. Larkin, J.G.; Capell, H.A.; Sturrock, R.D. Seatone in rheumatoid arthritis: A six-month placebo-controlled study. Ann. Rheum. Dis. 1985, 44, 199-201. [CrossRef] [PubMed]

53. Puente, R.; Illnait, J.; Mas, R.; Mendoza, S.; Carbajal, D.; Fernández, J.; Mesa, M.; Prieto, Y. Effects of d-002, a mixture of beeswax alcohols, co-administered with green-lipped mussel extract, on osteoarthritis symptoms. Int. J. Pharm. Sci. Rev. Res. 2014, 27, 209-216.

54. Cho, S.H.; Jung, Y.B.; Seong, S.C.; Park, H.B.; Byun, K.Y.; Lee, D.C.; Song, E.K.; Son, J.H. Clinical efficacy and safety of lyprinol, a patented extract from new zealand green-lipped mussel (perna canaliculus) in patients with osteoarthritis of the hip and knee: A multicenter 2-month clinical trial. Eur. Ann. Allergy Clin. Immunol. 2003, 35, 212-216. [PubMed]

55. Rajkumar, H.; Mahmood, N.; Kumar, M.; Varikuti, S.R.; Challa, H.R.; Myakala, S.P. Effect of probiotic (vsl\#3) and omega-3 on lipid profile, insulin sensitivity, inflammatory markers, and gut colonization in overweight adults: A randomized, controlled trial. Mediat. Inflamm. 2014, 2014, 348959.

56. Yu, H.N.; Zhu, J.; Pan, W.S.; Shen, S.R.; Shan, W.G.; Das, U.N. Effects of fish oil with a high content of n-3 polyunsaturated fatty acids on mouse gut microbiota. Arch. Med. Res. 2014, 45, 195-202. [CrossRef] [PubMed]

57. Balfego, M.; Canivell, S.; Hanzu, F.A.; Sala-Vila, A.; Martinez-Medina, M.; Murillo, S.; Mur, T.; Ruano, E.G.; Linares, F.; Porras, N.; et al. Effects of sardine-enriched diet on metabolic control, inflammation and gut microbiota in drug-naive patients with type 2 diabetes: A pilot randomized trial. Lipids Health Dis. 2016, 15, 78. [CrossRef] [PubMed]

58. Patterson, E.; O’Doherty, R.M.; Murphy, E.F.; Wall, R.; O'Sullivan, O.; Nilaweera, K.; Fitzgerald, G.F.; Cotter, P.D.; Ross, R.P.; Stanton, C. Impact of dietary fatty acids on metabolic activity and host intestinal microbiota composition in c57bl/6j mice. Br. Nutr. 2014, 111, 1905-1917. [CrossRef] [PubMed] 
59. Kaliannan, K.; Wang, B.; Li, X.Y.; Kim, K.J.; Kang, J.X. A host-microbiome interaction mediates the opposing effects of omega-6 and omega-3 fatty acids on metabolic endotoxemia. Sci. Rep. 2015, 5, 11276. [CrossRef] [PubMed]

60. Ghosh, S.; DeCoffe, D.; Brown, K.; Rajendiran, E.; Estaki, M.; Dai, C.; Yip, A.; Gibson, D.L. Fish oil attenuates omega-6 polyunsaturated fatty acid-induced dysbiosis and infectious colitis but impairs lps dephosphorylation activity causing sepsis. PLoS ONE 2013, 8, e55468. [CrossRef] [PubMed]

61. Bui, T.P.; Ritari, J.; Boeren, S.; de Waard, P.; Plugge, C.M.; de Vos, W.M. Production of butyrate from lysine and the amadori product fructoselysine by a human gut commensal. Nat. Commun. 2015, 6, 10062. [CrossRef] [PubMed]

62. Rios-Covian, D.; Ruas-Madiedo, P.; Margolles, A.; Gueimonde, M.; de Los Reyes-Gavilan, C.G.; Salazar, N. Intestinal short chain fatty acids and their link with diet and human health. Front. Microbiol. 2016, 7, 185. [CrossRef] [PubMed]

63. Basson, A.; Trotter, A.; Rodriguez-Palacios, A.; Cominelli, F. Mucosal interactions between genetics, diet, and microbiome in inflammatory bowel disease. Front. Immunol. 2016, 7, 290. [CrossRef] [PubMed]

64. Pusceddu, M.M.; El Aidy, S.; Crispie, F.; O’Sullivan, O.; Cotter, P.; Stanton, C.; Kelly, P.; Cryan, J.F.; Dinan, T.G. N-3 polyunsaturated fatty acids (pufas) reverse the impact of early-life stress on the gut microbiota. PLoS ONE 2015, 10, e0139721.

65. Noriega, B.S.; Sanchez-Gonzalez, M.A.; Salyakina, D.; Coffman, J. Understanding the impact of omega-3 rich diet on the gut microbiota. Case Rep. Med. 2016, 2016, 6. [CrossRef] [PubMed]

66. Nakada, H.I.; Wolfe, J.B. Glucosamine degradation by Escherichia coli. II. The isomeric conversion of glucosamine 6-po4 to fructose 6-po4 and ammonia. Arch. Biochem. Biophys. 1956, 64, 489-497. [PubMed]

67. Gómez de Segura, I.A.; Valderrábano, S.; Vázquez, I.; Vallejo-Cremades, M.T.; Gómez-García, L.; Sánchez, M.; de Miguel, E. Protective effects of dietary enrichment with docosahexaenoic acid plus protein in 5-fluorouracil-induced intestinal injury in the rat. Eur. J. Gastroenterol. Hepatol. 2004, 16, 479-485. [CrossRef] [PubMed]

68. Rani, I.; Vaiphei, K.; Agnihotri, N. Supplementation of fish oil augments efficacy and attenuates toxicity of 5-fluorouracil in 1,2-dimethylhydrazine dihydrochloride/dextran sulfate sodium-induced colon carcinogenesis. Cancer Chemother. Pharmacol. 2014, 74, 309-322. [CrossRef] [PubMed]

69. Torres, D.M.; Tooley, K.L.; Butler, R.N.; Smith, C.L.; Geier, M.S.; Howarth, G.S. Lyprinol only partially improves indicators of small intestinal integrity in a rat model of 5-fluorouracil-induced mucositis. Cancer Biol. Ther. 2008, 7, 295-302. [CrossRef] [PubMed]

70. Sebe, M.; Tsutsumi, R.; Yamaguchi, S.; Horikawa, Y.T.; Harada, N.; Oyama, T.; Kakuta, N.; Tanaka, K.; Tsutsumi, Y.M.; Nakaya, Y.; et al. The synergystic effects of omega-3 fatty acids against 5-fluorouracil-induced mucosal impairment in mice. BMC Nutr. 2016, 2, 17. [CrossRef]

71. Janczyk, W.; Socha, P.; Lebensztejn, D.; Wierzbicka, A.; Mazur, A.; Neuhoff-Murawska, J.; Matusik, P. Omega-3 fatty acids for treatment of non-alcoholic fatty liver disease: Design and rationale of randomized controlled trial. BMC Pediatr. 2013, 13, 85. [CrossRef] [PubMed]

72. Huang, K.-H.; Nichols, R.G.; Sebastian, A.; Albert, I.; Patterson, A.D.; Ross, A.C. Gut microbiota increased by omega-3 fatty acids is negatively correlated with hepatic lipid metabolism-associated genes in mice with high carbohydrate diet-induced steatosis. FASEB J. 2017, 31, 654.3.

73. Juliano, C.; Manconi, P.; Cossu, M. Characterisation of commercial perna canaliculus samples and development of extemporaneous oral veterinary paste formulations containing perna. Nat. Prod. Res. 2016, 30, 2041-2048. [CrossRef] [PubMed]

(C) 2017 by the authors. Licensee MDPI, Basel, Switzerland. This article is an open access article distributed under the terms and conditions of the Creative Commons Attribution (CC BY) license (http://creativecommons.org/licenses/by/4.0/). 